\title{
9 Complexity and Language Contact: A Socio-Cognitive Framework
}

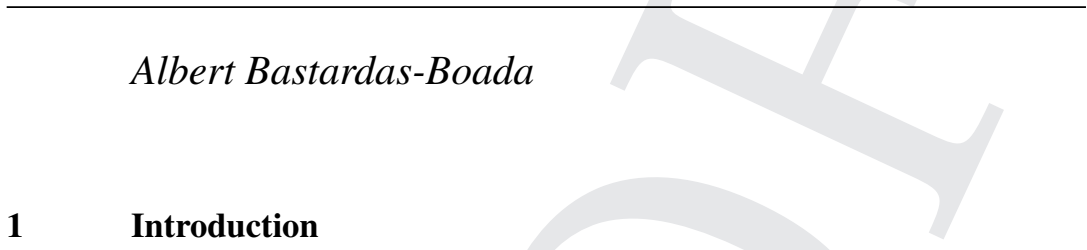

Throughout most of the twentieth century, analytical and reductionist approaches have dominated in biological, social, and humanistic sciences, including linguistics and communication. We generally believed we could account for fundamental phenomena in invoking basic elemental units. Although the amount of knowledge generated was certainly impressive, we have also seen limitations of this approach. Discovering the sound formants of human languages, for example, has allowed us to know vital aspects of the 'material' plane of verbal codes, but it tells us little about significant aspects of their social functions. I firmly believe, therefore, that alongside a linguistics that looks 'inward' there should also be a linguistics that looks 'outward', or even one that is constructed 'from the outside', a linguistics that I refer to elsewhere as 'holistic' (Bastardas 1995), though it could be identified by a different name. My current vision is to promote simultaneously the perspective that goes from the part to the whole and goes from the whole to the parts, that is, both from the top down and from the bottom up (see Bastardas 2013).

This goal is shared with other disciplines which recognise that many phenomena related to life are interwoven, self-organising, emergent and processual. Thus, we need to re-examine how we have conceived of reality, both the way we have looked at it and the images we have used to talk about it. Several approaches now grouped under the label of complexity have been elaborated towards this objective of finding new concepts and ways of thinking that better fit the complex organisation of facts and events.

\subsection{Complexity/Complexities}

The use of the term complexity in science poses serious difficulties if we do not first clarify the sense in which we are using it. The reason is that this label has been taken up by a variety of disciplines and schools of thought. Thus, it has been attached to perspectives, phenomena and aspects of reality that do not dovetail very well with one another, which creates a good deal of confusion that must be dispelled at the outset. 
The most frequent initial confusion is the use of the term complexity to refer not to a given scientific approach, but to an intrinsic quality of many of the phenomena of reality. In layman's language, complexity or complex is customarily used to signify complication, confusion, intricacy, diversification or a large number of units and rules in play. For instance, we speak of the complexity of a country or of a society, and the complexity of the human body or brain, or of a specific language. Complexity, in these sorts of uses, does not refer so much to a particular way of conceiving reality as to a feature of specific phenomena of the world that we wish to understand.

In linguistics, the application of the term complexity has largely focused on the structural and grammatical features of human languages, particularly the comparative study of their grammatical systems. In other words, the focus has been on the existing diversity in the number of units used and their characteristics and combinations at different levels of verbal codes as well as how they change and develop over time (see, for example, Sampson et al. 2009; Nichols 2009; Emmert-Streib F. 2010; McWorther 2011).

As previously observed, from a scientific point of view, and starting from different fields and distinct lines of research, several authors have been constructing a paradigm that has also come to be known as the sciences (or theory) of complexity (e.g. Morin 1980, 1991, 1992, 1994, 1999, 2001; Wagensberg 1985; Gell-Mann 1996; Cilliers 1998; Gershenson \& Heylighen 2005; Castellani \& Hafferty 2009; Mitchell 2009; Jörg 2011). This is only one and perhaps the most appropriate name from among others currently available, including cybernetics (Wiener 1948; Ashby 1956; Bateson 1972; Heylighen 2001), systemics (Von Bertalanffy 1981; Capra 1982), ecology (Margalef 1991), chaosology (Flos 1995; Bernárdez 1995), autopoiesis or self-organisation (Maturana \& Varela 1996; Maturana 2002; Solé \& Bascompte 2006), emergentism (Holland 1998; Johnson 2002), and networks science (Newman et al. 2006; Solé 2009).

In this approach, the terms complexity and complex are used to refer in general to a characteristic typical of a great number of elements and phenomena of reality: an organisation comprised of interwoven units that give rise to new and emergent levels of organisation and (inter)actions, with properties and capabilities that are distinct from those of the initial constituent elements. With this type of phenomena, there is a high degree of awareness that any application of a more or less mechanistic picture is fraught with difficulty, because of the vast number of dynamic inter-retro-actions produced, which prompt the emergence of new organisational levels that have different functions and, at the same time, integrate functionally with other coexisting phenomena.

However, even within the theory or science of complexity approach itself, there are important distinctions to make. On the one hand, we have a perspective that focuses more on modelling and computation. On the other, the focus is 
more epistemological and philosophical, that of the pensée complexe, inspired primarily by Edgar Morin. Morin (2007) called these two sets of approaches, respectively, 'restricted' (complexité restreinte) and 'general' complexity.

Turning now to the more methodological and formalist approaches, the science of complexity has made important contributions connected to the potentialities of computing and to the appearance of new forms of mathematical reasoning that better suit complex and dynamic phenomena with a high degree of interactivity and mutual emergent feedback. In recent decades, physicists, mathematicians, computer scientists and some biologists and sociologists, principally, have been the driving force in important lines of research and thought devoted to studying the formal properties, potentialities and characteristics of 'complex systems'. This 'synthetic' method - as it has been called by Luc Steels (1995) to distinguish it from inductive and deductive methods - offers us something different from what we have seen so far: a chance to understand the genesis and development of phenomena (see e.g. Abrams \& Strogatz 2003; Ball 2005; Newman et al. 2006).

This method involves simulating complex processes with agent-based programs that model behaviours generally governed by simple rules that are themselves usually based on 'if stimulus, then response' formulations (cf. Wolfram 1983, 2002; Epstein 2006; Castelló et al. 2011). Such 'complex adaptive systems' (CAS) ${ }^{1}$ can also learn from their relationships with the context in order to adapt better (by more adequately making use of the environment in order to take full advantage of it for their own purposes).

\subsection{Agents and Models in Language Contact}

Some researchers have already started to apply the computational tools to language contact and bilingualism (e.g., Loureiro et al., chapter 8; Castelló 2010; Castelló et al. 2013). The model typically uses squares in a computer screen to depict agents governed by simple rules of conduct they apply in accordance with any other types of agents with which they come into contact. After a given number of iterations, the result at the level of language will be the greater or lesser use of one or another of the coexistent languages. For instance, if one of the groups of agents is more predisposed to use its second language to speak with members of the other group than to use its first language, we can see on screen how such a situation will evolve.

One of the contributions of these types of methodologies is that they enable us to clearly visualise the bottom-up phenomenon of sociocultural organisation that emerges from interactions among agents (Holland 1998). We can clearly

${ }^{1}$ Although the term has grown in popularity due to the efforts of the Santa Fe Institute, it should be remembered that the sociologist Walter Buckley was using it as early as 1967. 
see how, based on the application of a few stable rules, social behaviours can shape a society's customs and other cultural aspects. The complex concept of self-organisation (Ashby 1962; Solé \& Bascompte 2006) is highly useful for understanding historical developments, including the evolution of language. This is also true for the evolution of networks (Sole 2009), which enable us to account for cultural variations that can be produced in accordance with the configuration of the web of relations that individuals maintain with one another.

Thus, this type of modelling lets us literally see, on screen, in silico, the process of reduction in the use of a language, showing agents who are applying rules that they do not suspect will potentially generate negative consequences over time and ultimately the practical extinction of what was once their first language. The strategy of simulation, therefore, is a productive one, surpassing classical statistical tools to the extent that it enables us to control the parameters of an evolving situation and what emerges out of that situation. ${ }^{2}$

As for the second set of approaches, 'general' complexity (Morin 1992, 1994, 2008) is more heavily committed to an epistemological, multidimensional, integrated and dynamic view of reality: the world is constituted by the 'emergent' overlap of different elements that produce new properties or organisations as they complexify at higher levels. And this may go on from initial physical and genetic elements all the way up to human societies and cultures. It postulates that in order to gain an adequate understanding of the interwoven fabric of all these domains in motion, we need to go beyond a way of thinking that tends to separate the elements of reality and treat them in isolation. It pushes us beyond reductionist thinking that prioritises the elementary units and quantitative aspects of phenomena. It calls for us to think in terms of 'both/and' and not 'either/or', applying fuzzy logic (Munné 2013) rather than Aristotelian logic. It demands that we sidestep the pitfalls of dichotomies, and it builds from the fact that complex thinking is not the 'opposite' of simple thinking, but rather incorporates it ${ }^{3}$ (Bastardas 2002).

In linguistics, there are also contributions that have arisen between these two major positions, building on the viewpoint of 'complex adaptive systems' from the Santa Fe Institute but seeking to go beyond computational modelling,

2 Not only simulations, but also programmes of this type using real data have been run to validate a theoretical model. One example is the use of cellular automata to examine the processes of language shift in Spain in a study devised by the group led by Francesc S. Beltran, using data from the autonomous community of Valencia (2009 and 2011). The model assumes social pressure the number of people in the neighbourhood who encourage one behaviour or another - to be one of the fundamental variables in the evolution of the sociolinguistic situation, and this allows us to view the evolution of intergenerational language transmission.

3 It must be conceded that the use of the terms complex and complexity in the vast majority of publications appearing in English - the most widespread language of science - corresponds much more to 'restricted' complexity than to the more general perspective. For instance, the activity of researchers at the Santa Fe Institute (Gell-Mann, Holland, etc.) has been immense and extremely interesting. At present, this approach is also seeing a generous crop of developments in Europe. 
toward interesting theoretical propositions like the ones put forward by Holland (2005), The 'Five Graces' Group (2009) or Massip-Bonet (2013). Similarly, the ecology-inspired contributions of Mufwene $(2001,2008,2013)$ take a broad perspective consistent with the approaches of general complexity. In economics, for example, the work of Brian W. Arthur (2013) takes a very open view also.

The general-complexity perspective aims not so much to devise precise theories about specific phenomena as it sets out to take a comprehensive view of reality, a view that is holistic and, at the same time, mindful of the autonomous parts. From this viewpoint, in the words of Castellani and Hafferty:

Social complexity theory is more a conceptual framework than a traditional theory. Traditional theories, particularly scientific ones, try to explain things. They provide concepts and causal connections (particularly when mathematicised) that offer insight into social phenomenon (...) Scientific frameworks, by contrast, are less interested in explanation. They provide researchers effective ways to organize the world; logical structures to arrange their topics of study; scaffolds to assemble the models they construct (2009:34).

Certainly, the two perspectives of complexity go together, but they correspond to distinct levels and emphases, and they need to be complementary and integrated. Recently, authors have taken this task in hand and are able to offer their reflections to us. This is the case, for example, with Malaina (2012), Rodríguez Zoya (2013), Roggero (2013), Ruiz Ballesteros (2013), Solana (2013), and Byrne \& Callaghan (2014), who deeply take both traditions into consideration, integrating and evaluating them. Although computational methods and strategies are useful to illuminate how human situations evolve, including situations of language contact, it would be hard to go so far as to say that restricted complexity needed to be the foundation on which to build a broad and complex vision of sociocultural reality. In any event, it should be the other way round. Our perspective ought to be built on the epistemological and representational foundations of general complexity, and we need to use the methods, tools and concepts of restricted complexity on the phenomena and processes that they can best shed light on. ${ }^{4}$

Based on general complexity, my approach explores the world in a way that helps us understand how language contact phenomena unfold. What follows is my personal synthesis of the main principles of the complexity perspectives in contrast with the more traditional scientific ones. The concepts listed in the following two columns are not necessarily opposites.

4 '[W]e do not consider that mathematical representations of the social represent some ideal towards which social science should be aiming. (...) Mathematics can be a useful tool for describing the reality but reality is its messy self, not a higher abstract order existing in mathematical form. (...) When we approach the complex social we need methods which can take accounts of context, agency and temporality' (Byrne \& Gallaghan 2014:257). 


\begin{tabular}{ll}
\hline \hline Traditional Scientific Perspective & General Complexity Perspective \\
\hline conceptual reification & $\begin{array}{l}\text { there is no science without an observer } \\
\text { (centrality of brain/mind) }\end{array}$ \\
\hline territory & maps (we see by means of concepts and words) \\
\hline scientific truth & provisional theories \\
\hline elements & $\begin{array}{l}\text { elements-and-contexts, interweaving, } \\
\text { figurations, interdependences, networks }\end{array}$ \\
\hline objects & events and processes \\
\hline steady-state & dynamic flux, change, evolution, development \\
\hline classical logic & fuzzy logic \\
\hline linear causality & circular, retroactive and nonlinear \\
& causality, recursivity \\
\hline either/or dichotomies & both/and; integration and complementarity \\
\hline top-down and planned creation & bottom-up, self-organisation and emergence \\
\hline unidimensionality & inter-influential multidimensionality \\
\hline 'explicate order' (things are unfolded and & 'implicate order' (everything is folded into \\
each thing lies only in its own particular & $\begin{array}{l}\text { everything; a hologram: the parts contain } \\
\text { region of space) }\end{array}$ \\
\hline fragmentation of disciplines & intermation on the entire object) \\
\hline structure, code & meaningful and emotional interaction \\
\hline \hline
\end{tabular}

Figure 9.1 Main principles of the complexity perspectives in contrast with the more traditional scientific ones

\section{A Socio-Cognitive Complexity Perspective on Language Contact ${ }^{5}$}

In principle, it is not easy to apply the perspective of general complexity to understanding the co-determinants and evolution of language behaviours in situations of intense language contact. Quite often, the study of these cases draws on a sociolinguistic tradition that focuses more on fragmentary aspects for example, bilingual competences, code-switching, identities, policies, and so on - than on a comprehensive view that is dynamic and transdisciplinary. By contrast, our proposal aims to provide the basis of an integrative focus, from a perspective of human socio-complexity which draws on the contributions of traditional approaches to the study of language systems, but goes beyond them.

One possible way to envisage an integrated study of the complexity of evolving conditions in situations of language contact is to conceive of them from an

5 In this chapter, I will not go into the specific effects of contact over and above habitual language forms, such as the phenomenon of interference, language borrowing or change. 
ecological point of view (Haugen 1972; Mackey 1979, 1980, 1994). Margalef (1991:80) calls an ecosystem:

a level of reference formed by individuals together with the materials that are produced by their activity ( ...) and the matrix or physical surroundings in which they are included and in which they act.

The assumption of the ecosystem concept is that the fate of a particular linguistic variety - that is, its survival, its alteration, or its extinction - depends basically on the evolution of the sociocultural factors that are involved in its production. Its structure, then, is basically governed by the social functions that it is required to perform. This is, in fact, a characteristic of the complex adaptive systems. As Holland states, 'the context in which a persistent emergent pattern is embedded determines its function' (1998: 226).

Consequently, this approach sees the relation between languages and linguistic groups as a three-way (rather than a two-way) phenomenon. In conceiving the relation between two species, for example, the ecological perspective bears in mind at all times the milieu in which the relation develops. This perspective is vitally important to understand the impact of migration on language contact, or the integration of a politically minoritised group in a state, as it underscores the need to take into account the structure of the broad sociopolitical environment as well as the groups in question.

Another principle on which this approach is based is that the different orders and phenomena of the reality make up an interrelated whole, in which there are not only circular, mutual influences between two variables but also a set of dynamic interactions that make up the reality, as explained later. Thus mental, interactional, collective, economic, political, and linguistic phenomena coexist in such a way that one constitutes the other and vice versa. To express the image, I use the metaphor of the musical score which enables us to visualise different planes of the same unitary phenomenon and which exists sequentially, that is, in time.

The static image of reality is also challenged. Contrary to the traditional approach, time is an essential, continually present variable. Apparent stability is always the result of a dynamic equilibrium that allows the conservation of the identity of the units even if their elements are changed. More than as a structure, reality should be seen as a set of events, or, to quote Bohm, as a 'universal flux of events and processes' (1987:31).

From this perspective the fragmentation into disciplines is also questioned. As reality is multidimensional, an inter- and transdisciplinary focus is necessary, especially in the sociocultural sciences. The new conceptual landscapes must then allow the integration of perspectives of the different approaches in a global theorisation which considers simultaneously all the necessary levels of human beings in an integrated, coordinated way (see Capra 1982, 1996, 
2002). In fact, the inspiration for this approach comes not only from outside but also from inside the sociocultural sciences. According to Bastide (1971:8), Auguste Comte himself seems to have suggested as much in an era that lacked the conceptual instruments required for an ecological or complex approach: 'In the natural sciences the elements exist before the whole; in the human sciences, the whole exists before the parts' (contemporary physicists make the same claim for quantum physics). Twentieth-century authors, such as Gregory Bateson (1972), Norbert Elias (1982, 1990, 1991), Kurt Lewin (1978), and Walter Buckley $(1967,1968)$, declare their support for an approach of this kind, albeit from different angles. The report of the Gulbenkian Commission on the reorganisation of the social sciences (1996), chaired by Immanuel Wallerstein, clearly pointed in the same direction, as well as all the works by Edgar Morin. Uriel Weinreich would agree:

It is in a broad psychological and sociocultural setting that language contact can best be understood. ( ...) On an interdisciplinary basis research into language contact achieves increased depth and validity (Weinreich 1968: 4).

Noteworthy is also the fact that the orchestral complexity metaphor enables us to understand and to organise in separate and yet interrelated ways the dimensions which are most relevant to determining the behaviour of humans in situations of linguistic diversity and contact. So, as an exploratory example, we will construct a pentagram for each of the voices or instruments without forgetting their interrelation with the other pentagrams among which relations of harmonic interdependence arise. ${ }^{6}$ For the moment, and in a brief and simplified image, our score will comprise the following emergent and superposing basic parts: the minds, social interaction, human groups, and political power (Bastardas 1996). Language varieties 'live' and interact with these dimensions.

\section{The Co-Environment of Linguistic Varieties}

\subsection{The Brain/Mind Complex}

As John Holland says, 'If we are to understand the interactions of a large number of agents, we must first be able to describe the capabilities of individual agents; (1996:7). Consequently, little can be understood about human

\footnotetext{
6 In the orchestral score one can see the evolutions of each of the instruments or voices and of the whole that results from the superimposition of one on the other in the interpretative sequence of the work. This is no more than applying the vision of systems, where each level forms part of a whole of multiple interrelated levels, the cooperation of all of which produces the emergence of a specific behaviour or global product able to be perceived by and to influence another human being.
} 
behaviour if we do not begin our examination of the metaphorical score by looking at the 'brain/mind complex', since it is at this level that the ultimate control over human action and understanding lies. Let us, therefore, take the human being as a bio-social product endowed with a brain/mind that will enable and regulate the individual's relationship with the world ${ }^{7}$ (see Maturana \& Varela 1996).

The usual development of the neurocognitive complex occurs - and out of necessity must occur - in close interrelation with the sociocultural context, in other words, through interaction with other human predecessors and their products. Without this requisite activation, during the optimum phase, of the genetic programming by the stimuli of social activity, no brain can develop properly or have any chance of recovery during its lifetime. In all probability, the interrelationship between the developing brain/mind and the sociocultural phenomenon can be seen more accurately in terms of self-organising systems rather than in terms of the computer metaphor, with its traditional inputs and outputs (Varela et al. 1992:157). The fruit of this functional autonomy is that the brain/mind will construct itself from the perceived cultural artefacts derived from the social interactions, so that, as Morin suggests, it is a complex phenomenon formed from inseparable elements - the brain/mind, the individual and the society/culture - each of which, in its own way, contains the others (1986:84). This approach also helps to advance our anthropological understanding, given that our cultural knowledge is to be found - as it would appear to be in reality - at the interface of these elements rather than in one or in all of them (Varela et al. 1992:178).

In socialisation, the structure of the sociocultural contexts represents a factor of considerable influence on the final results of this process. If someone comes across different ways of speaking in the set of contexts in which he or she lives, the degree and quality of development in each of these linguistic varieties might differ according to the type and the intensity of exposure or use. The variety or varieties used in the family setting - in particular that of the mother or person(s) who spend(s) the most time with the child in the first year of his or her life - will supply the initial elements for the development of comprehension and expression. It/They will tend to become the code or codes that will form the base for the conceptual structuring of reality, for the development of the collective identity of the individual and - if the social context does not impede it - for the informal linguistic communication ability of the person.

If the remaining social contexts - neighbours, networks of friends, pupils at school, teachers, the mass media, and so on - confirm the way of speaking the individual has acquired in the family - and/or at the kindergarten, which

7 Unlike the physical sciences, at the level of human phenomena it is not only the mind of the observer that we should take into account, but the minds of the subjects of the observation as well. We should take account of the mind not merely because of its intrinsic importance, but because it is inside the mind that the great majority of the courses of action of humans are determined. 
these days acts in part as a substitute for these contexts - the individual will gradually expand his competence in this code. He will acquire the registers corresponding to the different functions and situations and then will use them as a matter of course in his daily communicative acts with no problem whatsoever. If, on the other hand, the individual finds other distinct varieties outside the initial context of socialisation, then he will be presented with a problem of a different nature with complex causes and consequences. Thus, if, for example, the variety developed in the family setting is neither spoken nor understood in all the other contexts, the individual will be obliged to acquire as quickly as possible the other way(s) of speaking and will become bi- or multilingual or bi- or polylectal if they are varieties of the same language. ${ }^{8}$ In this type of situation the individual might finally develop a greater degree of competence in his second variety than in his first - in particular, if exposure to the latter occurs during the critical period and, if, in addition to the informal contexts, the new variety is also that of the formal public contexts - the medium of formal education, of the general street signs, of the media, and so on.

In terms of understanding linguistic behaviour, there are two main interrelated functions of the brain/mind complex that would appear to be of particular relevance: the representation of reality and control over behaviour. It is in the brain/mind complex where we construct and sustain ideas about the reality that we experience, and from where we activate our motor organs to carry out specific actions - determined in accordance with the discursive representations and interpretations of the reality that we make (Van Dijk 2010). And this we can do, as we shall see, either from the conscience or the 'subconscience'. We can hold certain definitions of reality without being conscious of so doing, and similarly we can undertake certain actions without having been conscious before, or at the time, of having done so. The conscience, therefore, does not exhaust the mind. Many of our mental acts are not directly accessible from the conscience. $^{9}$

${ }^{8}$ Individuals might also find two (or more) systems of linguistic communication within the family domain. The most typical case is that which occurs where each progenitor uses a different language to address the child. In such situations, and if the person-language norm is consistent, the child should be able to develop more or less equally the bases of two mother tongues (Weinreich 1968:77), and will use them appropriately according to the situation (Fantini 1982:63).

9 In fact, as Popper and Lorenz (1992:30) pointed out, learning includes the effort of consigning what one has just learnt to the subconscience. Thus, a large part of our behavioural and cognitive activity is subconscious. The high degree of consciousness that we maintain over each action when learning to drive a car becomes part of a routine and our subconscience when we have some experience and we wish to centre our attention on the road. We must conclude, therefore, that the phenomenon also affects linguistic behaviour and all other human activities. Indeed, Bateson believes that the conscience must always be limited to a rather small fraction of mental process. (...) The unconsciousness associated with habit is an economy both of thought and of consciousness; and the same is true of the inaccessibility of the processes of perception. The conscious organism does not require (for pragmatic purposes) to know how it perceives - only to know what it perceives $(1972: 136)$. 
At the heart of this conception of the human being as a cognitiveinterpretative being is, as maintained by the perspective of symbolic interactionism, the view that 'the meaning does not emanate from the intrinsic makeup of the thing that has meaning but rather from and through the defining activities of the people as they interact' (Blumer 1969:4). Things do not have meaning on their own; rather, it is human beings that attribute meaning to things, be they physical objects, words or actions, through the cognitive processing of apprehended information and internalised interpretative procedures. Facing any perception and, frequently, from our subconscience, the world is processed and understood drawing on the available cognitive depository. Any perception that cannot be recognised and interpreted from the knowledge available at that time will activate the conscience in order to produce a hypothesis that makes sense, that might explain what it is that we are perceiving, how it relates with our other perceptions, what function it performs, for whom, and the like. As Schutz said,

I cannot understand a cultural object without referring it to the human activity in which it originates. For example, I do not understand a tool without knowing the purpose for which it was designed, a sign or symbol without knowing what it stands for in the mind of the person who uses it, an institution, without understanding what it means for the individuals who orient their behaviour with regard to its existence (1974:41).

While human beings develop direct referential interpretative capacities in relation to the linguistic structures perceived in their social interactions, they also develop social evaluative interpretations of these same linguistic structures, in particular in situations of diversity of ways of talking. Therefore, speaking in one or another variety, or using each other's linguistic form, might be socially significant and have major repercussions on the interaction that develops. Just as we can assign meanings to the social status of the clothes that we wear, the linguistic varieties used can also be associated with specific social meanings. When we interpret our perceptions, we do so polyphonically, multidimensionally. Virtually never do we consider one level of meaning in isolation; we integrate within our pertinent perceptions or information, and, what is more, from within a hierarchical organisation.

The social meanings of the linguistic forms are part of the individual's cognitive-interpretative stock and can thus influence the action both of the potential user and the interlocutor. The latter might, for example, not offer room to someone who speaks in a way that is considered negative socially. Therefore, the individual that is perceived negatively might decide, for example, to abandon the linguistic variety that is disadvantageous, perhaps especially when it is also derided.

From out of this context of competences, meanings, habitus and unconscious routines, the individual will choose specific language forms to use in communication with other people. As we can see, for example, individuals in 
situations of social bilingualism will use one code or another in line with the representation they have of their interlocutor, the available competences (of the two individuals), the social meanings of the varieties to hand, their previously established custom, and their cognitive interpretation of the context in which the interaction takes place. The sum total of behavioural decisions taken by the individuals of a given society will mark the evolving dynamic of the situation.

\subsection{The Level of the Social Interaction of Brains/Minds}

Individual brains/minds are also, at the same time, the building blocks of a higher level of complexity, which emerges naturally from the properties of its constituents but adds new features that are typical and characteristic of the new interactional dimension and of the social situations in which this dimension is produced. Thus, at this level, there are all the elements that we have identified as belonging to the brain/mind complex as well as all those that arise from the need for organisation at the level of interaction.

Thus, social interaction must be viewed as an inextricably socio-mental relation and therefore cognitive and interpretative in nature. If, in normal circumstances, human action is given meaning by a subject who can actively form interpretations through observation and perception, then any interaction is necessarily mutually significant. Actions, movements, gestures, verbalisations, paraverbal elements, the language forms and varieties that are being used, the situations in which these occur, the biographical precedents of the relation, expected intentions, and other factors will be a constant source of conscious or unconscious interpretations processed holistically between interacting individuals (Serrano 1993). Understanding the social organisation of interpersonal relations becomes crucial to understanding enormously important aspects of language behaviour.

In many cases, human interactions are well organised, quite often predictable within given limits, and meaningful. Daily encounters tend to unfold according to socially established norms and rituals that coordinate social life so that we do not have to improvise behaviour each time we come into contact with another human being and so that we can adequately interpret our interaction. Though self-organisation constantly applies in daily interactions, it is not a simple fact or at least a fact easy to describe in detail.

The entire complex of behaviours will be interpreted holistically by the interlocutors in terms of the instructions of 'scripts' for various social settings, which determine the extent to which the behaviours fit socially habitual expectations. If the 'script' for a given ceremony calls for a given level of formality of apparel, for example, a person wearing clothing categorised by the social majority as 'informal' may be judged negatively. This negative assessment, however, will be attenuated or even changed if other significant aspects of the 
same person are valued positively, such as his or her way of talking, gestures or accessories, or if the person has a convincing reason for dressing in this way.

Once adopted and established sociocognitively, the most daily, regular and repetitive norms of action generally become subconscious and are followed routinely, almost automatically in most cases (Nisbet 1977). Such actions include how to greet someone, what to say and what to do when departing a place, how to structure a conversation, and also what language or variety to use when speaking with a particular person.

A relation between individuals typically tends to establish fixed patterns of behaviour between the two participants. For example, if at some time we adopt the custom of kissing at each meeting and we repeat this behaviour for a certain number of days, it is highly likely to become a norm and, therefore, an expectation that must be satisfied at each meeting in the future. Similarly, once we have, by mutual agreement, adopted a given language behaviour and more or less confirmed it by periodic repetition, the selection of the variety or language becomes subconscious and routine; and it will tend to be perpetuated. Indeed, at some point, changing the variety or language will become extremely difficult.

In social situations involving language diversity, selecting the variety or language to use is not a simple action. An initial factor that can influence this selection is the language competence of the individuals involved. If two individuals can only understand and speak one variety, they will use it in all likelihood. However, if they also understand and speak another one, the choice is more complex. They may choose to use either one. That is, the two individuals are likely to negotiate the variety to be used, because it is common in communicative relations to prefer the use of one and only one variety by both individuals, provided that their mastery is sufficient to make this possible (Hamers \& Blanc 2000; Hamers 2004). Presumably, if there is a discrepancy, the negotiation is won by the interlocutor who is more persuasive. If each interlocutor remains firm in his own position, the ensuing interactions will involve the two interlocutors speaking different languages - what has been called 'bilingual conversation' - or the interlocutors will tend to avoid interactions so as not to reproduce the conflict each time they communicate.

Although language behaviour tends to be decided subconsciously and routine, the possibility always exists to bring it back to the conscious level and control it directly and reflectively by the individual, overcoming the constraints of competence and habitual behaviour, if desired (Bastardas 1995). Of course, this also entails social consequences, negative and positive, that may arise from the individual's decision. For example, individuals may decide that it is better for them to change their manner of speaking with specific people or in general, using individual words or constructions, a different variety of the same language or a different language, rather than speaking as they always have. 
This fact lies behind many of the ways in which sociolinguistic situations evolve.

As we shall see next, factors belonging to higher levels of organisation (e.g., the group or political level) exert an influence at the interactional level as a result of the complex interdependence across the various domains of the sociolinguistic ecosystem. Thus, an individual's language behaviour can be affected not only by elements at the interactional level such as the necessary organisation of the use of varieties in conversation, but also by elements such as the issue of identity in relation to the language groups in contact or the regulation of public uses implemented by the political authorities. Both domains can influence the language choices made by individuals in their interactions, in accordance with their representations of reality.

\subsection{The Social Group Dimension}

3.3.1 The Emergence of Networks and Groups Not only are human societies organised by interactional pairs but also their members interact with a greater number of people with whom they co-construct in complex ways a new level of reality, a 'groupness' that shapes many of the aspects of what we call 'culture' as opposed to 'nature'. These individuals-in-society, as Norbert Elias would say, take advantage of the potentialities of the brain to build networks and together consolidate forms of sociocultural and communicative organisation that will adapt to the changing nature of their collective historical experiences. The group, therefore, will usually be the basic unit of survival and social control, setting standards that will constrain individual and collective action. In the group, Morin's idea of recursiveness is at work; that is, the individual makes up the group that makes up the individual. Once it has formed, a group tends to persist if it is a functional organisation and it benefits individual members. Thus, cause and product maintain and change one another.

The existence of groups and limited networks of intense interaction gives rise to the possibility of cultural diversity. Each network can autonomously create representations and establish forms and norms of conduct that differ to varying degrees from those adopted by other collectives. More specifically, groups differ in the degree of importance they give to specific elements of daily life, in the behaviours they deem appropriate in various situations, in the language forms they use or prefer to use, and so on. Cultural and linguistic diversity is a real, well-established fact.

Sociocultural categorisation plays a significant role in decisions that individuals make to take joint action. As members of socially, economically and culturally stratified urban societies, we always interpret others as members of some social group or category that is the same as or different from our own, with the ensuing normative and evaluative associations, and we make decisions 
about our actions based on such associations. In ethno-linguistic conflicts it is crucial to distinguish situations characterised by political subordination from conflicts produced by mere territorial co-existence. In the first case, the conflict is typically based on the expansionism of a demographically or militarily stronger group into a neighbouring territory inhabited historically by other collectives with different cultures. In the second case, groups cohabit regularly in the same territory and some discord arises from some reason within or outside the groups. Both cases can generate a high level of awareness of ethnic identity within the collectives in conflict, and this awareness can have an effect on any possible inter-group behaviours, because ethnic identity, according to Barth, 'is similar to sex and rank, in that it constrains the incumbent in all his activities, not only in some defined social situations' (1976:18).

In inter-group relations, the system of linguistic communication that is used may become highly significant. It may come to act as an ethnic identifier, with the consequences that that identification entails. Similarly, the overall configuration of ethnicity and inter-group relations may have an effect at the level of language. For subordinate groups, a positive ethnic consciousness can be the reason for maintaining their language, while a negative one is the most common cause for them to abandon it. The differences, for example, in the evolution of the sociolinguistic situation of Catalonia and the Valencian Community, in Spain, are probably based on that factor, which itself is due to other elements, like differences in the history of their economic development (Ninyoles 1978; Aracil 1982).

Many ethnolinguistic groups that have been incorporated in larger political units, often forced by historical events, are typically structured according to the environment of another ethnolinguistic group which can control and 'patrimonialise' the political power by virtue of its demography or some other strength. These groups wind up accepting or rejecting their involvement at the level of identity in a larger body they are part of, on which they depend economically and politically, and yet which they perceive as alien to their own self-defined cultural characteristics. A more or less significant segment of the population may move toward full acceptance of the superordinate identity, accepting it as basic, while the original ethnic identity comes to be viewed as secondary. At the other extreme, another segment may see the matter in the opposite manner: native cultural traits are fundamental and primary; given that these traits are typically in decline in the face of traits associated with the polity in which the ethnic group is found, the cultural forms represented by the state and the state itself lose legitimacy and are rejected. A third position may also arise in which individuals contrive a combination of identities and find greater compatibility between the group categories in conflict. We can see all these evolutions in the current cases of language contact in Spain (Siguan 1993; Coller 2006; Strubell $\&$ Boix-Fuster 2011). 
3.3.2 Groups and the Macrosocial Order The dimension of POWER, like that of SOCIAL CATEGORY, is constantly present in social life and is an absolutely central element in the changing fortunes of groups. Typically, human groups do not have identical controls over economic, informational, demographic, or political resources. An awareness of the differences often comes with inter-group comparisons. A habitual way of speaking that is associated with a particular group of high socioeconomic status, for example, may be admired or rejected according to how it is perceived by other groups it coexists with. Certain ways of speaking among the upper classes can be ridiculed by members of other social groups and vice versa. In other situations, members of social groups at the lower end of the social scale can have self-negating representations that spur in them the desire to adopt the language traits of economically higher social groups in order to raise their own personal prestige and improve their self-image. Indeed, as Pierre Bourdieu $(1980,1984)$ points out very effectively, social positions are closely related to the predispositions - the representational and behavioural habitus - of the individuals who occupy those positions. This fact can often be the cause of more or less large-scale shifts in the language behaviour of individuals aiming to emulate the language forms that are more closely identified across the entirety of the society as belonging to affluent, socially dominant groups.

In today's information society, the greater or lesser possession of cultural or symbolic goods (e.g. academic training, skills in the arts or high technology or specialised knowledge of diverse types) is also a factor of social differentiation that is not purely economic in nature. Intellectual elites can also constitute social groups that are perceived and evaluated as having prestige by a large part of the population, particularly by the middle and working classes. As a result, they can have a significant influence on the evaluation and use of specific language forms. Through institutionalised roles occupied by virtue of political power or social structure, they convey to the population whose forms shall be considered legitimate and valuable in public discourse. A minority population in a subordinate position can easily shift cultures, a phenomenon that has occurred frequently in all periods of history.

\section{$3.4 \quad$ Political Power}

We have seen how human beings construct new sociocognitive realities basically in a self-organised manner. They hold representations based on facts of the world, reaching a consensus on the forms of their interactions and forming cultural and economic groupings. The culmination of contemporary developed societies is their organisation into states, which are not based specifically on phenomena of self-organisation, but rather on an explicit, formal act of establishment. At this level, particular individuals - sometimes elected 
democratically and sometimes not - are able to exercise significant power over many aspects of social life. It is a fact that the contemporary state intervenes more than ever in the life of human communities and exercises an enormous influence. The level of language not only fails to escape its influence but rather, contrary to what one may think, can be highly controlled and determined by political power.

Specifically in the area of language, the impact of political power is both direct and indirect. Because the state can require the compulsory fulfilment of its provisions, the explicit or implicit declaration of an 'official language' will result in the codification of the selected variety or varieties, assuming they were not previously codified. It will also extend their knowledge and use to public functions across the entire territory where they are named. Typically, even without explicit regulation, the variety selected as an official language will also tend to be adopted in the remainder of public communication that is not dependent on the state government. Quite often, it will be the only variety that citizens consciously and reflectively learn and the only one readily available for them to use in formal speaking and writing. As a result, it will de facto become the language variety that can be used comprehensively in institutionalised communications (Corbeil 1983) within the area over which the state exercises sovereignty. It may even be used in private writing to a great extent. Moreover, as we shall see, the linguistic characteristics of the official variety may eventually be adopted even in informal spoken communication, particularly in cities, where the process of urbanisation also entails both the destruction of local sociocultural ecosystems and the need to adopt new norms of communication in the complex urban environment.

In phenomena of language contact, the state can be particularly critical to how situations evolve, because the linguistic pressures brought to bear by the regulation of the official status of languages can play a crucial role in the maintenance or abandonment of the varieties in contact. When a state with a multiethnic population identifies itself solely with one of its ethnolinguistic groups, the situation is a source of potential conflicts between the state and the dominant ethnolinguistic group, on the one hand, and smaller ethnolinguistic groups, on the other hand, like in Spain during General Franco's rule. The political will of the state to unify its citizens linguistically can crash head on into communities that often prefer to stick to their own language varieties, varieties whose structures may differ sharply from those of the official language. Such communities, which may have a historical awareness of collective differentiation, may not be ready to accept a homogenising policy. If the history also includes forced annexation, economic or religious differentiation and a policy of national uniformity pursued at the expense of the languages and cultures of smaller groups, the conflict can be prolonged and acute. Under these conditions, the politicisation of the ethnolinguistic reality is inevitable, because the state is the 
instrument needed by an ethnolinguistic group wishing to become a 'nation' or even simply to protect itself from assimilation. The state's political subordination of some of its constituent populations is the fundamental cause of many processes of language shift, which are nothing more, in such cases, than the displacement of the traditional language varieties of smaller groups toward disuse, privileging the official standard varieties sponsored by the state.

\section{$4 \quad$ Ecosystem Dynamics}

So far we have drawn the lines of the orchestral or polyphonic score that can be used metaphorically to develop a dynamic view of the processes of language contact from the perspective of complexity. This means that we will understand the evolving outcome of these types of processes much better if we see them as a consequence of the mutual influences of the various lines in the score, that is, of the conflict or reconciliation of different pressures present in the sociocultural ecosystem (Terborg \& García-Landa 2013).

Thus, for example, if we want to gain a holistic understanding of the development of sociolinguistic situations such as in Catalonia, we should simultaneously consider all levels: their complex interdependences and the changes occurring over time. We can clearly observe interrelations among the distinct domains, for example, in the process of restoring the Catalan language undertaken by the government of Catalonia. While the public school system seeks to expand knowledge of Catalan (and Spanish) among a population in which one segment has Catalan as L1, another segment has Spanish as L1, and a further growing segment has a mother tongue other than these two, the degree of success in increasing the interpersonal use of the autochthonous language is relative. The reason is that there are complex factors at play that have their own, hard-to-change dynamics. On the interactional level, for example, there is a very widespread habit among L1 Catalan speakers to accommodate L1 Spanish speakers and not vice versa - a behaviour that is also being taken up by a large proportion of the younger generations and becoming readily automatic and unconscious. What is occurring at this level would seem to contradict what is happening at the group level, where there is a growing awareness of Catalan identity, at least in the group of L1 Catalan speakers. Contrary to what might be expected, however, this is not carrying over to the level of language behaviour adopted with L1 Spanish speakers who have already become bilingual - at least within the school context - in Catalan. The brain's mechanisms of memory and routine formation appear to play such a fundamental role that once a language choice for speaking with a person has been made, the choice is typically repeated in new encounters, even throughout an entire lifetime and sometimes in contexts that were considered inappropriate. One example of this 
can be seen in partners of mixed linguistic origins who get to know each other in Spanish and continue using Spanish with one another throughout their lives, even though they speak Catalan to their children. The opposite may also occur, as we more often see in the Valencian case, when partners speak Catalan to each other, but speak Spanish to their children (Querol 1990; Conill 2003; Montoya $\&$ Mas 2012).

A complex, multidimensional perspective enables us to grasp much better why there are some processes in which state policies prevail and populations adopt the code that has been declared official, while there are other cases in which this does not occur so easily. Apart from the previously cited elements of routinisation and the subconscious, emotional collective identifications and cognitive self-images also come into play in the acceptance or rejection of a state language. If a language group views and experiences a state's language policy as illegitimate, for example, because its own language is not given official recognition, it can tend to reject the policy and prefer not to use the state language. On the other hand, if the group sees an opportunity in the state language to make social and economic progress and it has negative representations of its own code, it will tend to adopt this language much more readily.

The emphasis placed by the perspective of complexity on the time and processuality of phenomena is also highly useful in grasping how different situations evolve. In the case of Catalonia, for example, it is evident that current difficulties in further expanding the use of Catalan have their roots in the path dependence on earlier events. As the Franco dictatorship achieved a high level of bilingualisation in Spanish among L1 Catalan speakers in a context in which the public use of Catalan was banned, Catalan speakers largely grew accustomed to using Spanish with L1 Spanish speakers coming to reside in Catalonia, particularly in the city of Barcelona. Now, the established habit is deeply ingrained and much more difficult to change, despite explicit campaigns with coherent arguments about the danger posed for the future of Catalan. In addition, a complex, systemic view can more adequately explain why the group of L1 Spanish speakers increases their interpersonal use of Catalan less, given the fact that the earlier adaptation of L1 Catalan speakers leaves them no opportunities to use Catalan, despite government efforts (Boix-Fuster \& Farràs 2013).

The biological replacement of populations through generational change is also of major importance in how processes of contact evolve. New individuals who replace those who came before can be socialised in a context distinct from their parents and cognitively adopt new representations that prompt them to shift to the prevailing behaviours. As complex adaptive systems, the younger generation may already be more habituated to contact with another group than their own parents, for example, and they may develop the language skills needed in a situation of contact earlier on, at a time that is more biocognitively 
optimal. Economic contexts, too, can evolve and come to exert influence on the social meanings and attitudes ascribed to language varieties, which can in turn lead to the adoption of new behaviours. Viewing these issues from a complex perspective is not only useful but necessary.

Consequently, it is of special importance to stress that language contact must be understood as a historical and, therefore, temporal phenomenon, with earlier events playing a major role in how the phenomenon evolves. In other words, we need to pay attention not only to the synchronic elements, but also to the diachronic ones, because the latter may determine the future development of the phenomenon (Elias 1982).

\section{$5 \quad$ Conclusion}

We have seen some examples of how restricted and general complexity perspectives can help understand the interwoven mechanisms of sociolinguistic dynamics at work in cases of contact. Given its holistic view and its mindfulness of its own parts, the suggested image of the orchestra that we have used as a metaphor can enable us to integrate the micro and macro (i.e., respectively, inter-individual and institutional) dimensions present in human experience and reflect the mutual interdependencies of the participating levels. What this can encompass ranges widely from genetic to sociopolitical constraints, and simultaneously, it takes into consideration the presence of time as an inescapable context for the emergence and existence of language forms and varieties.

From the general complexity perspective we must emphasise the cognitive and emotional uniqueness of human agents and not lose sight of the importance of this factor in their (inter)actions. In addition, the human social organisation itself makes linguistic/communicative activity ever present in a variety of areas and specific contexts that also exert a reverse influence on the linguistic level. The human linguistic phenomenon is at one and the same time an individual, social and political fact. As such, its study should bear in mind these complex interrelations, produced inside the framework of the sociocultural and historical ecosystem of each human community.

The complexity of these interrelationships, their multidimensionality and the numerous factors that can affect their evolutionary dynamics will not make it easy to apply tools in the field of linguistics that are also valid for other, less complex phenomena. For example, the methods and concepts of restricted complexity can be used as supplementary strategies that are highly useful in studying certain characteristics, the stages and speeds of processes of language contact, but always within the frame of the broader view offered by general complexity.

Methodologically, this use of computational instruments specific to restricted complexity ideally needs to be accompanied by the combined use of 
qualitative strategies, because without such strategies we cannot gain access to the sociocultural meanings that individuals confer to their language forms and to the representations by which they experience the events of their lives (Mead 1934; Bruner 1990). From the perspective of general complexity, conducting comparative case studies is an interesting strategy in this regard and it also complements approaches that are based more on statistics and formal modelling (Byrne \& Callaghan, 2014). Complexity aims to overcome fragmentary methodological views. It postulates their harmonious integration in the service of attaining the deepest possible understanding of phenomena as a whole. As stated by Byrne and Callaghan:

[W] e see complexity as providing a framing for the unifying of a whole set of opposites in scientific practice, of quantitative and qualitative research, of analysis and holism as modes of understanding, and of relativism and hard realism as epistemological position (Byrne \& Callaghan, 2014:255).

In order to develop paradigms, the two major complexity approaches need to find more common ground and take steps toward a mutual integration based on the acceptance of the shortcomings of each approach, achieving progress through a non-contradictory complementarity of perspectives (Heylighen, Cilliers \& Gershenson 2007; Bastardas 2014). It must be conceded that the practical and methodological applications of basic complexity ideas need to be developed much farther in order to apply them to specific research. As Roggero has noted:

[t]oday, there are more experts in formal disciplines taking an interest in the social sphere than there are sociologists borrowing the techniques of the formal disciplines. If a meeting of minds takes place, it will turn out to be hugely beneficial for both groups. The first will need to learn sociology's language and ways of thinking, including the sociological culture; the second will have to contend with the formal rigour, the methodological demands and the utilisation of useful computer tools found in the formal disciplines (2013:116).

At the same time, the limits of complex adaptive systems as computational strategies must be accepted in the pursuit of a better understanding of the evolutionary processes typical of human beings. In the final analysis, models always have a narrative running behind them that reflects the attempts of a human being to understand the world, and models are always interpreted on that basis. This is precisely what Allen and Hoekstra have recognised in the field of ecology:

Narratives are the bottom line in science. Yes, there are hypotheses, predictions, theories and models, but all of these devices are in the service of achieving compelling narratives. (...) The end product of science is a story improved by models and made convincing by predictions (2014, forthcoming). 


\section{REFERENCES}

Abrams, Daniel M. \& Steven H. Strogatz. 2003. Modelling the dynamics of language death. Nature 424, 900.

Allen, Timothy F. H. \& Thomas W. Hoekstra. 2015. Toward a unified ecology, 2nd edn. New York: Columbia University Press.

Aracil, Lluís V. 1982. Papers de sociolingüística [Sociolinguistic papers]. Barcelona: La Magrana.

Arthur, W. Brian. 2013. Complexity economics: A different framework for economic thought. Available at www.santafe.edu/media/workingpapers/13-04-012.pdf.

Ashby, W. Ross. 1956. An introduction to cybernetics. London: Chapman \& Hall.

Ashby, W. Ross. 1962. Principles of the self-organizing system. In Heinz Von Foerster \& George W., Jr. Zopf (eds.), Principles of self-organization: Transactions of the University of Illinois Symposium, 255-278. London: Pergamon Press.

Ball, Philip. 2005. Critical mass: how one thing leads to another. London: Random House, Arrow Books.

Barth, Fredrik (comp.). 1976. Los grupos étnicos y sus fronteras. México: Fondo de Cultura Económica.

Bastardas-Boada, Albert. 1995. Language management and language behavior change: policies and social persistence. Catalan Review 9 (2), 15-38.

Bastardas-Boada, Albert. 1995b. Cap a un enfocament holístic per a la lingüística [Towards a holistic approach for linguistics]. In Rosa Artigas et alii (eds.), El significat textual [Textual meaning], 15-20. Barcelona: Generalitat de Catalunya, Departament de Cultura.

Bastardas-Boada, Albert. 1996. Ecologia de les llengües. Medi, contacte i dinàmica sociolingüística [Ecology of languages. Sociolinguistic environment, contact and dynamics]. Barcelona: Proa.

Bastardas-Boada, Albert. 2002. World Language Policy in the Era of Globalization: Diversity and Intercommunication from the Perspective of 'Complexity', Noves SL. Revista de Sociolingüística. Available at www6.gencat.net/llengcat/noves/ hm02estiu/metodologia/a_bastardas.pdf.

Bastardas-Boada, Albert. 2013. General linguistics and communication sciences: sociocomplexity as an integrative perspective. In Massip-Bonet \& Bastardas-Boada (eds.), Complexity perspectives on language, communication and society. Berlin: Springer, 151-173.

Bastardas-Boada, Albert. 2014. Towards a complex-figurational socio-linguistics: Some contributions from physics, ecology and the sciences of complexity, History of the Human Sciences 27 (3), 55-75. DOI: 10.1177/0952695114534425.

Bastide, Roger. 1972. Antropología aplicada. Buenos Aires: Amorrortu.

Bateson, Gregory. 1972. Steps to an ecology of mind. New York: Ballantine Books.

Beltran, Francesc S., Salvador Herrando, Doris Ferreres, Marc-Antoni Adell, Violant Estrader \& Marcos Ruiz-Soler. 2009. Forecasting a language shift based on cellular automata. Journal of Artificial Societies and Social Simulation 12(3), 1-8.

Beltran, Francesc S., Salvador Herrando, Violant Estrader, Doris Ferreres, Marc-Antoni Adell, \& Marcos Ruiz-Soler. 2011. A language shift simulation based on cellular automata. In Emmanuel G. Blanchard \& Danièle Allard (eds.), Handbook of research on culturally-aware information technology: perspectives and models, 136-151. Hershey / New York: Information Science Reference. 
Bernárdez, Enrique. 1995. Teoría y epistemología del texto. Madrid: Cátedra.

Bertalanffy, Ludwig von. 1969. General system theory. New York: George Braziller.

Blumer, Herbert. 1969. Symbolic interactionism: Perspective and method. Englewood Cliffs, NJ: Prentice-Hall.

Bohm, David. 1987. La totalidad y el orden implicado. [Spanish translation of Wholeness and the Implicate Order. London: Routledge \& Kegan Paul, 1980]. Barcelona: Kairós.

Boix-Fuster, Emili \& Jaume Farràs. 2013. Is Catalan a medium-sized language community too? In F. Xavier Vila (ed.), 157-178.

Bourdieu, Pierre. 1980. Le sens pratique. Paris: Éditions de Minuit.

Bourdieu, Pierre. 1984. Distinction: A social critique of the judgement of taste. Cambridge: Harvard University Press.

Bruner, Jerome. 1990. Acts of meaning. Cambridge, MA: Harvard University Press.

Buckley, Walter. 1967. Sociology and modern systems theory. Upper Saddle River, NJ: Prentice Hall.

Byrne, David \& Gill Callaghan. 2014. Complexity theory and the social sciences. The state of the art. London: Routledge.

Capra, Fritjof. 1982. The Turning Point. New York: Simon \& Schuster.

Capra, Fritjof. 1996. The web of life. A new synthesis of mind and matter. Hammersmith, London: HarperCollins, 1996.

Capra, Fritjof. 2002. The hidden connections. New York: Doubleday.

Castellani, Brian \& Frederic William Hafferty. 2009. Sociology and complexity science. Berlin: Springer-Verlag.

Castelló Llobet, Xavier. 2010. Collective phenomena in social dynamics: Consensus problems, ordering dynamics and language competition, doctoral dissertation. Palma de Mallorca: University of the Balearic Islands.

Castelló, Xavier, Federico Vazquez, Víctor M. Eguíluz, Lucía Loureiro-Porto, Maxi San Miguel, Laetitia Chapel \& Guillaume Deffuant. 2011. Viability and resilience in the dynamics of language competition. In Guillaume Deffuant \& Nigel Gilbert (eds.), Viability and resilience of complex systems, 39-74. Heidelberg: Springer.

Castelló, Xavier, Lucía Loureiro-Porto \& Maxi San Miguel. 2013. Agent-based models of language competition. International Journal of the Sociology of Language 221, 21-51.

Cilliers, Paul. 1998. Complexity and postmodernism. Understanding complex systems. London: Routledge.

Coller, Xavier. 2006. Collective identities and failed nationalism. The case of Valencia in Spain. Pôle Sud 25, 107-136.

Conill, Josep J. 2003. The situation of Valencian as reported in non-institutional sociolinguistic research (1998-2002). Noves SL. Revista de Sociolingüística, 1-9.

Corbeil, Jean-Claude. 1983. Élements d'une theorie de la regulation linguistique. In Édith Bedard \& Jacques Maurais (eds.), La norme linguistique, 281-303. Quebec \& Paris: Conseil de la Langue Française.

Elias, Norbert. 1982. Sociología fundamental. [Spanish translation of Was ist Soziologie? Munich, Juventa Verlag, 1970]. Barcelona: Gedisa.

Elias, Norbert. 1990. La sociedad de los individuos [Spanish translation of Die Gesellschaft der Individuen, 1987]. Barcelona: Península.

Elias, Norbert. 1991. The symbol theory. London: SAGE. 
Emmert-Streib, Frank. 2010. Statistic complexity: Combining Kolmogorov complexity with an ensemble approach. PLoS ONE 5(8), 1.

Epstein, Joshua M. 2006. Generative social science: Studies in agent-based computational modeling. Princeton, NJ: Princeton University Press.

Fantini, Alvino E. 1982. La adquisición del lenguaje en un niño bilingüe, Barcelona: Herder.

Flos, Jordi (ed.). 1995. Ordre i caos en ecología [Order and chaos in ecology]. Barcelona: Publicacions de la Universitat de Barcelona.

Gell-Mann, Murray. 1994. The Quark and the Jaguar: Adventures in the Simple and the Complex. New York: Henry Holt and Company.

Hamers, Josiane F. \& Michel H. A. Blanc. 2000. Bilinguality and bilingualism. Cambridge: Cambridge University Press.

Hamers, Josiane. F. 2004. A sociocognitive model of bilingual development. Journal of Language and Social Psychology 23 (1), 70-98, DOI: 10.1177/ $0261927 X 03261615$.

Gershenson, Carlos \& Francis Heylighen. 2005. How can we think the complex? In Richardson, K. (ed.). Managing organizational complexity: Philosophy, theory and application, vol. 3, 47-62. Charlotte, NC: Information Age Publishing.

Haugen, Einar. 1972. The Ecology of Language. In: Anwar S. Dil (ed.), The Ecology of Language, 325-339. Stanford: Stanford University Press.

Heylighen, Francis. 2001. The science of self-organization and adaptivity. In L. Douglas Kiel (ed.), Knowledge management, organizational intelligence and learning, and complexity. Encyclopedia of life supports systems. Oxford: Eolss Publishers.

Heylighen, Francis, Paul Cilliers \& Carlos Gershenson. 2007. Complexity and philosophy. In Jan Bogg \& Robert Geyher (eds.), Complexity, science and society, 117 134. Oxford: Radcliffe Publications.

Holland, John H. 1996. Hidden order. How adaptation builds complexity. New York: Basic Books.

Holland, John H. 1998. Emergence. From chaos to order. Cambridge, MA: Perseus Publishing.

Holland, John H. 2005. Language acquisition as a complex adaptive System. In James W. Minett \& William S-Y. Wang (eds.), Language acquisition, change, and emergence, 411-436. Hong Kong: City University Hong Kong Press.

Johnson, Steven. 2002. Emergence. London: Penguin Books.

Jörg, Ton. 2011. New thinking in complexity for the social sciences and humanities. Heidelberg: Springer.

Mackey, William F. 1979. Toward an ecology of language contact. In William F. Mackey \& Jacob Ornstein (eds.), Sociolinguistic studies in language contact, 453-460. La Haya: Mouton.

Mackey, William F. 1980. The ecology of language shift. In Peter Hans Nelde (ed.), Sprachkontakt und Sprachkonflikt, 35-41. Wiesbaden: Franz Steiner Verlag.

Mackey, William F. 1994. La ecología de las sociedades plurilingües. In Albert Bastardas Boada \& Emili Boix-Fuster (eds.), ?'Un estado, una lengua? La organización política de la diversidad lingüística, 25-54. Barcelona: Octaedro.

Malaina, Álvaro. 2012. Le paradigme de la complexité et la sociologie. Possibilité et limites d'une sociologie complexe. Paris: L'Harmattan.

Margalef, Ramon. 1991. Teoría de los sistemas ecológicos. Barcelona: Publicacions de la Universitat de Barcelona. 
Massip-Bonet, Àngels. 2013. Language as a complex adaptive system: Towards an integrative linguístics. In Massip-Bonet \& Bastardas-Boada (eds.), 35-60.

Massip-Bonet, Àngels \& Albert Bastardas-Boada (eds.). 2013. Complexity perspectives on language, communication and society. Heidelberg: Springer.

Maturana, Humberto. 2002. Autopoiesis, structural coupling and cognition. Cybernetics \& Human Knowing 9(3-4), 5-34.

Maturana, Humberto \& Francisco J. Varela. 1996. El árbol del conocimiento. Las bases biológicas del conocimiento humano. Madrid: Editorial Debate.

McWhorter, John H. 2011. Linguistic simplicity and complexity. Why do languages undress? Berlin: De Gruyter Mouton.

Mead, George H. 1934. Mind, self and society (Charles W. Morris, ed.). Chicago: The University of Chicago Press.

Mitchell, Melanie. 2009. Complexity: A guided tour. Oxford: Oxford University Press.

Montoya Abat, Brauli, \& Antoni Mas i Miralles. 2012. Language teaching and family linguistic transmission: Two correlative factors in the Valencian Region (Catalan vs. Spanish)? Sociolinguistic Studies 6(1), 45-63.

Morin, Edgar. 1980. La méthode. 2. La vie de la vie. Paris: Éditions du Seuil.

Morin, Edgar. 1986. La méthode. 3. La connaissance de la connaissance. París: Éditions du Seuil.

Morin, Edgar. 1991. La méthode. 4. Les idées. Leur habitat, leur vie, leurs moeurs, leur organisation. Paris: Éditions du Seuil.

Morin, Edgar. 1992. Introduction à la pensée complexe. Paris: ESF.

Morin, Edgar. 1994. La complexité humaine. Paris: Flammarion.

Morin, Edgar. 1999. La tête bien faite. Repenser la réforme, réformer la pensée. París: Éditions du Seuil.

Morin, Edgar. 2001. La méthode. 5. L'humanité de l'humanite. L'identité humaine. Paris: Éditions du Seuil.

Morin, Edgar. 2007. Restricted complexity, general complexity. (Translated from French by Carlos Gershenson.) In Carlos Gershenson, Diederik Aerts, \& Bruce Edmonds (eds.), World views, science and us. Philosophy and complexity, 5-29. Singapore: World Scientific.

Morin, Edgar. 2008. On complexity. Advances in systems theory, complexity, and the human sciences. New York: Hampton Press.

Mufwene, Salikoko S. 2001. The ecology of language evolution. Cambridge: Cambridge University Press.

Mufwene, Salikoko S. 2008. Language evolution. Contact, competition and change. New York: Continuum International.

Mufwene, Salikoko S. 2013. The emergence of complexity in language: An evolutionary perspective. In Massip-Bonet \& Bastardas-Boada (eds.), 197-218. Heidelberg: Springer.

Munné, Frederic. 2013. The fuzzy complexity of language. In Massip-Bonet \& Bastardas-Boada (eds.), 175-196.

Newman, Marc, Albert-László Barabási \& Duncan J. Watts. 2006. The structure and dynamics of networks. Princeton, NJ: Princeton University Press.

Nichols, Johanna. 2009. Linguistic complexity: A comprehensive definition and survey. In Geoffrey Sampson, David Gil \& Peter Trudgill (eds.), Language complexity as an evolving variable, 110-125. Oxford: Oxford University Press. 
Ninyoles, Rafael L. 1978. Conflicte linguistic valencià [Valencian linguistic conflict]. València: Eliseu Climent ed.

Nisbet, Robert. 1977. The social bond. New York: Random House.

Popper, Karl \& Konrad Lorenz. 1992. El porvenir está abierto. Barcelona: Tusquets Ed. (Spanish translation of Die Zukunft ist offen. Munic: E. Piper GmbH, 1985.)

Querol, Ernest. 1990. El procés de substitució lingüística: la comarca dels Ports com a exemple [Language shift process: Els Ports county as an example]. Miscel-lània 89, 87-196. València: Generalitat Valenciana.

Rodríguez Zoya, Leonardo G. 2013. Le modèle épistémologique de la pensée complexe. Analyse critique de la construction de la connaissance en systèmes complexes. Unpublished Ph. D. Thesis, Université de Toulouse.

Roggero, Pascal. 2013. Para una sociología según El método. In Ruiz Ballesteros \& Solana Ruiz (eds.), 103-123.

Ruiz Ballesteros, Esteban. 2013. Hacia la operativización de la complejidad en ciencias sociales. In Ruiz Ballesteros \& Solana Ruiz (eds), 137-172.

Ruiz Ballesteros, Esteban \& José Luis Solana Ruiz (eds.). 2013. Complejidad y ciencias sociales. Seville: Universidad Internacional de Andalucía.

Sampson, Geoffrey, David Gil \& Peter Trudgill (eds.). 2009. Language complexity as an evolving variable. Oxford: Oxford University Press.

Schutz, Alfred. 1974. El problema de la realidad social [Spanish translation of Collected papers: I. The problem of social reality. The Hague: Martinus Nijhoff, 1962]. Buenos Aires: Amorrortu.

Schutz, Alfred \& Thomas Luckmann. 1977. Las estructuras del mundo de la vida. Buenos Aires: Amorrortu. (Spanish translation of The Structures of the Life-World. Evanston, IL: Northwestern University Press, 1973).

Searle, John R. 1985. Mentes, cerebros y ciencia. Madrid: Ed. Cátedra. (Spanish translation of Minds, Brains and Science. The 1984 Reith Lectures, Cambridge, MA: Harvard University Press.)

Serrano, Sebastià. 1993. Comunicació, societat i llenguatge [Communication, society and language]. Barcelona: Empúries.

Siguan, Miquel. 1993. Multilingual Spain. Amsterdam: Swets-Zeitlinger.

Simon, Herbert A. 1962. The architecture of complexity. Proceedings of the American Philosophical Society 106 (6), 467-482.

Solana Ruiz, José Luis. 2013. El concepto de complejidad y su constelación semántica. In Esteban Ruiz Ballesteros \& José Luis Solana Ruiz (eds.), Complejidad y ciencias sociales, 19-101. Seville: Universidad Internacional de Andalucía.

Solé, Ricard. 2009. Redes complejas. Del genoma a internet. Barcelona: Editorial Tusquets.

Solé, Ricard V. \& Jordi Bascompte. 2006. Self-organization in complex systems. Princeton, NJ: Princeton University Press.

Steels, Luc \& Rodney Brooks (eds.). 1995. The artificial life route to artificial intelligence. New Haven, CT: Lawrence Earlbaum.

Strubell, Miquel \& Emili Boix-Fuster (eds.). 2011. Democratic policies for language revitalisation: the case of Catalan (Palgrave studies in minority languages and communities). Basingstoke: Palgrave Macmillan.

Terborg, Roland \& Laura García-Landa. 2013. The ecology of pressures: Towards a tool to analyze the complex process of language shift and maintenance. In MassipBonet \& Bastardas-Boada (eds.), 219-239. 
The 'Five Graces' Group: Beckner, Clay, Richard Blythe, Joan Bybee, Morten H. Christiansen, William Croft, Nick C. Ellis, John Holland, Jinyun Ke, Diane LarsenFreeman \& Tom Schoenemann. 2009. Language is a complex adaptive system. Language Learning 59, 1-26.

Van Dijk, Teun V. 2010. Discourse and context. A sociocognitive approach. Cambridge: Cambridge University Press.

Varela, Francisco J., Evan Thompson \& Eleanor Rosch. 1992. The Embodied Mind. Cognitive Science and Human Experience. Cambridge, MA: The MIT Press.

Vila, F. Xavier (ed.). 2013. Survival and development of language communities. Prospects and challenges. Clevedon, UK: Multilingual Matters.

Wagensberg, Jorge. 1985. Ideas sobre la complejidad del mundo. Barcelona: Tusquets editores.

Wallerstein, Immamnuel (ed.). 1996. Ouvrir les sciences sociales. Rapport de la Commission Gulbenkian. Paris: Descartes \& Cie.

Watzlawick, Paul, John H. Weakland \& Richard Fisch. 1974. Change. Principles of Problem Formation and Problem Resolution. New York: Norton.

Weinreich, Uriel. 1968. Languages in contact. The Hague: Mouton.

Wiener, Norbert. 1948. Cybernetics or control and communication in the animal and the machine. Cambridge \& Massachusetts: The MIT Press.

Wolfram, Stephen. 1983. Statistical mechanics of cellular automata. Reviews of Modern Physics 55(3), 601-644.

Wolfram, Stephen. 2002. A new kind of science. Champaign: Wolfram Media. 